\title{
GEODETIC ASPECTS OF GPS PERMANENT STATION NON-LINEARITY STUDIES
}

\author{
Janusz BOGUSZ
}

Faculty of Civil Engineering and Geodesy, Military University of Technology, Kaliskiego 2, 09-908 Warsaw, Poland

*Corresponding author's e-mail: janusz.bogusz@wat.edu.pl

\section{ARTICLE INFO}

Article history:

Received 16 January 2015

Accepted 26 June 2015

Available online 24 July 2015

Keywords:

GPS

Wavelets

Subduction zones

Permanent station's velocity

\begin{abstract}
This analysis is focused on the investigation on non-linearity in the GNSS (Global Navigation Satellite System) permanent stations coordinate time series with the use of wavelet transform. Standard applicable procedures for the determination of the velocity components are based on a GPS (Global Positioning System) time series assuming its linearity. Topocentric time series do not follow the stationarity, being a combination of the stochastic part composed of random relations as well as deterministic, strictly dependent on the past variations. Moreover, the assumption of trend linearity may result in the misestimation of its value with an influence on its uncertainty. One of the solutions to decompose the analysed time series is to apply wavelets. The daily position changes derived from GPS data covering approximately from 13 to 19 years for 5 permanent IGS (International GNSS Service) stations located in the tectonically unstable areas (subduction or spreading zones) were analysed to investigate long-term changes. The PPP (Precise Point Positioning) solutions generated at the JPL (Jet Propulsion Laboratory) using the GIPSY-OASIS software were used. The long-term trend was determined using wavelet decomposition based on the Meyer's orthogonal and symmetric wavelet and $R^{2}$ coefficient of determination was used here to estimate how well data fits a statistical model. Although the discovered peak-to-peak amplitudes of non-linearity in the last approximation (denoted here as A9) are not as high (several centimetres) in comparison to linear approximation, they still remain variable in time and will have an influence on the station's linear velocity. It was found that the trend is definitely non-linear for the selected (North, East or Up) components. The verification was performed on a so called "double stations" LHAS/LHAZ (Lhasa, Tibet/China), with only 4 metres apart. Two stations located next to each other recording similar long-term changes at the same time strongly prove the trend non-linearity for stations in tectonically active areas. The GPS-derived velocity inversions using wavelet approximation could be successfully compared to the elastic deformation that was predicted e.g. with finite elements modelling that approximates the geometry of the subduction, spreading or transition zones.
\end{abstract}

\section{INTRODUCTION}

Over the last two decades space techniques have provided reliable information about motion in the deformation zones (e.g. Erdoğan et al., 2009; PérezPeña et al., 2010; Altamimi et al., 2012; Caporali et. al., 2013 or Wang et al., 2013) as well as the velocity gradient tensor (Kreemer et al., 2014). The prevailing observations are the deformation of upper parts of the plates and the migration of the trench (Husson, 2012). In most subduction zones, the motion of the subducting plate is nearly perpendicular to the trench axis (Fig. 1), but at some stations the seismic coupling could provide also movement nearly parallel to the trench (e.g. Turner et al., 2007). Additional vertical deformation is also common.

The widely applied procedure estimates movement by the imposing motion in the direction of subduction on the bottom of the upper plate by the calculated GPS velocities with their linearity assumption (e.g. Mann et al., 2002; Hashimoto et al., 2009). Standard applicable procedures to determine velocity are based on a GPS time series assuming its linearity. Correa-Morra et al. (2009) used GPS velocities to investigate the motion of the region between an oceanic trench and its associated volcanic arc (forearc), regions that are found at convergent margins. In total 32 permanent GNSS stations located in El Salvador, Honduras and Nicaragua were taken into consideration. The GPS analysis software GIPSY-OASIS was used to determine daily station coordinates. Geodetic velocities were then determined using a best-fitting linear model eliciting values from 14 to 16 mm/yr. ten Brink and Lopez-Venegas (2012) used the horizontal components of continuous GPS measurements from 10 stations on Caribbean Islands to evaluate strain accumulation along the North American-Caribbean plate boundary. They used data obtained from the UNAVCO archive for a period of 2.75-5 years ending in August 2011 at sampling rates of 10,15 or $30 \mathrm{~s}$ to evaluate the seismic potential of the Puerto Rico Trench. Stebnov et al. (2010) used the collected geodetic data to reveal the geometry of interplate coupling along the Kuril-Kamchatka Arc. To compare the models predicted velocities with surface measurements they minimized the root mean square difference of the measured velocities. They used GPS 
data located at three (Eurasian, North American and Pacific) tectonic plates, which allowed a solution to the inverse problem: recovering the geometry of the coupled zone. Shih et al. (2008) determined the statistical model from absolute displacement derived from GPS measurements carried out in Taiwan over nearly 8 years. They found that time series of position components and displacement determined using Bernese software showed that a linear trend is progressively increasing. They also found that the results of linear regression reveal a consistency between the GPS-derived data and the statistical model. Cross and Freymueller (2007) used GPS measurements in the first geodetic study of plate coupling on the Andreanof segment, which is a part of the Aleutian subduction zone. They estimated linear site velocities in ITRF2000 reference frame and then converted to velocities relative to the North America plate using the REVEL2000 (Sella et al., 2000) model. Following that they used both horizontal and vertical velocities in the inversion for finding the plate-coupling coefficients (one minus the slip between the two plates expressed in terms of a unit plate convergence rate) using a gridded search inversion procedure. Chlieh et al. (2004) used the GPS daily solution obtained using the GLOBK software, from a French-Chilean project with the aim of a better understanding of the mechanics and kinematic processes associated with earthquake cycles in the northern Chile subduction zone. They concluded that recent velocities of the GPS stations located in this region, showing temporal variations in the years 19951996 and 1996-1997, and located on the coast as well as further inland suggested that a disorganized deformation field motion occurred in that area. Yoshioka et al. (2004) investigated GPS time series from 7 permanent stations located in Mexico for determining the optimal smoothness of them. They used a Bayesian Information Criterion (BIC) based on the Entropy Maximization Principle (EMP), which is a criterion for model selection among a finite set of models. Finally, they estimated the displacement rate for each component during the inter-seismic period.

GPS-related time series do not conform to stationary, being a combination of the stochastic part composed of random relations as well as deterministic, strictly dependent on past variations. One solution to decompose the time series under investigation is to apply wavelets. This method is defined by the mathematical functions that decompose the original signal into different scales and resolutions, and, consequently, making data analysis possible not only in frequency, but also in the timedomain (Mallat, 1980). One of the first applications of wavelet-based analysis to GPS data was made by Collin and Warnant (1995) who applied the wavelet transform for GPS cycle slip correction and compared the results with those obtained using Kalman filtering. Satirapod et al. (2001) applied a method based on wavelets to decompose GPS double-differenced residuals into a low-frequency bias term and a highfrequency noise term to improve the ambiguity resolution and the accuracy of estimated baseline components. The method proved to be very efficient, since the statistics in ambiguity validation testing were improved by at least $283.3 \%$. De Souza et al. (2009) applied wavelet to the modelling of the multipath effect to correct functional mathematical models. Wavelet transform is seen as a powerful technique to analyse all kinds of non-stationary signals related to the widely understood Earth sciences, including geodesy and geodynamics (Keller, 2004).

This work is also a continuation of the previous research conducted within Military University of Technology Local Analysis Centre (MUT LAC)and concerning monitoring of neotectonic changes using the GPS system (Figurski et al., 2009). The accuracies of the GGOS (Global Geodetic Observing System) products required by the most demanding users concerning terrestrial reference frames are: "accurate to $1 \mathrm{~mm}$, stable to $0.1 \mathrm{~mm} / \mathrm{yr}$, including geocenter; scale accurate to $0.1 \mathrm{ppb}$, stable to $0.01 \mathrm{ppb} / \mathrm{yr}^{\prime}$ " (Gross et al., 2009). Concerning the reliability at the level of the station EPN (EUREF Permanent Network) guidelines recommend moving station to A (the highest) class, when the formal uncertainty of the last velocity estimate is below $0.5 \mathrm{~mm} / \mathrm{y}$ (Bruyninx et al., 2013).

\section{DATA AND METHOD}

In this research I used the XYZ geocentric time series expressed in the ITRF2008 reference frame (Altamimi et al., 2011) were generated by members of the JPL (Jet Propulsion Laboratory) Geodynamics and Space Geodesy Group using the GIPSY-OASIS software (Webb and Zumberge, 1997) in a Precise Point Positioning mode. Pre-analysis of the daily coordinate time series supplied by JPL contained identification of the outliers using Median Absolute Deviation (MAD) criterion and Sequential T-test Analysis of Regime Shifts (STARS) algorithms for offsets previously successfully used by several authors (e.g. Bruni et al., 2014). It is widely acknowledged that consistency of GPS time series is degraded by the presence of offsets, outliers and gaps. They could be of different origin: natural - earthquakes, snow coverage, etc., or artificial - change of the equipment, power failure etc. Their identification and subtraction for the further analysis is crucial. More details about this issue could be found in Williams (2003), Gazeaux et al. (2013) or Klos et al. (2015). Gaps shorter than 40 days were interpolated using linear trend, annual and semi-annual sine functions determined from the non-interpolated data as well as white noise with an amplitude equal to the variance of each time series, on a separate basis.

This analysis is focused on the investigation of non-linearity in the GPS-derived time series with the use of wavelet transform. The wavelet transform 
Table 1 The frequency boundaries of the determined details (D1-D9) and last signal approximation (A9).These were approximated with cycles per year (cpy) and corresponding duration in days, months or years.

\begin{tabular}{ccc}
\hline Description & From & To \\
\hline A9 & $0.3 \mathrm{cpy} / 3.0$ years & infinity \\
D9 & $0.9 \mathrm{cpy} / 1.1$ years & $0.3 \mathrm{cpy} / 3.0$ years \\
D8 & $1.8 \mathrm{cpy} / 7$ months & $0.7 \mathrm{cpy} / 1.4$ years \\
D7 & $3 \mathrm{cpy} / 4$ months & $1.3 \mathrm{cpy} / 9$ months \\
D6 & $7 \mathrm{cpy} / 2$ months & $2.5 \mathrm{cpy} / 5$ months \\
D5 & $15 \mathrm{cpy} / 24$ days & $4.5 \mathrm{cpy} / 3$ months \\
D4 & $30 \mathrm{cpy} / 12$ days & $10 \mathrm{cpy} / 37$ days \\
D3 & $60 \mathrm{cpy} / 6$ days & $20 \mathrm{cpy} / 18$ days \\
D2 & $110 \mathrm{cpy} / 3$ days & $35 \mathrm{cpy} / 10$ days \\
D1 & $180 \mathrm{cpy} / 2$ days & $70 \mathrm{cpy} / 5$ days \\
\hline
\end{tabular}

provides a framework to decompose original time series into a number of new time series, each one of them with a different degree of resolution. For this research we used symmetric and orthogonal Meyer's wavelet (equations 1 and 2) due to its compactness in the frequency domain. It is defined in the frequency domain as (Meyer, 1990):

$\Psi(\omega)=\left\{\begin{array}{cc}\frac{1}{\sqrt{2 \pi}} \sin \left[\frac{\pi}{2} \nu\left(\frac{3|\omega|}{2 \pi}-1\right)\right] \exp \left(\frac{j \omega}{2}\right) & \text { for } \frac{2 \pi}{3}<|\omega|<\frac{4 \pi}{3} \\ \frac{1}{\sqrt{2 \pi}} \cos \left[\frac{\pi}{2} v\left(\frac{3|\omega|}{4 \pi}-1\right)\right] \exp \left(\frac{j \omega}{2}\right) & \text { for } \frac{4 \pi}{3}<|\omega|<\frac{8 \pi}{3} \\ 0 & \text { otherwise }\end{array}\right.$

where $v$ is an auxiliary function. There are many different ways for defining this function, which yields variants of the Meyer wavelet. For this analysis I used own-written functions in Matlab software, which adopts standard implementation of:

$v(x)=\left\{\begin{array}{cc}x^{4}\left(35-84 x+70 x^{2}-20 x^{3}\right) & \text { if } 0<x<1 \\ 0 & \text { otherwise }\end{array}\right.$

It also allows the complete reconstruction of the original signal by adding the individual frequency components and the final approximation (Popinski, 1996). The signal is decomposed simultaneously using a high-pass filter, with the outputs giving the detail coefficients (from the high-pass filter) and approximation coefficient (from the low-pass). Number of details (D) depends on the sampling rate and length of the time series. For JPL data it was decided to separate 9 details (D1-D9), details from 6 to 9 (Table 1) were assumed to cover the residual Chandler, annual, semi-, ter- and quarter-annual oscillations, which are widely recognized to be present in GPS time series (Collilieux et al., 2007; Blewitt and Lavallée, 2002 or Bogusz and Figurski, 2014). The last signal approximation (A9) was analysed further as the one theoretically representing the permanent station's movement.

There are many numerical artefacts in GPS-derived time series, which could come from the mismodelling in the short (tidal) periods (e.g. Dong et al., 2002; Penna and Stewart, 2003; Bogusz and Figurski, 2012) or from GPS orbiting (draconitic) period (e.g. Agnew and Larsson, 2007; Ray et al., 2008; Amiri-Simkooei, 2013). Griffiths and Ray (2013) tabulated aliasing periods. From this juxtaposition it follows that the maximum aliasing period is 385.98 days. In our case this would be "inside" detail D9. We deal with approximation A9 from 3 years to infinity. In this range there are neither physical oscillations (Chandler - 433 days) nor artificial (aliasing or draconitic - 351.6 days), for the same reason we also do not have to deal with aliasing between particular details.

Then all details from D1 to D9 were removed from the original data (assumed as being the sum of all noises and residual periodicities - all frequencies from 2 days up to 3 years) and last approximation analysed in terms of non-linearity. In the previously described research the linearity of the station's velocity was assumed. In most cases, this assumption may be correct, but it should not be treated as a rule. Moreover, the assumption of the linearity may hide useful information stored in the data. 

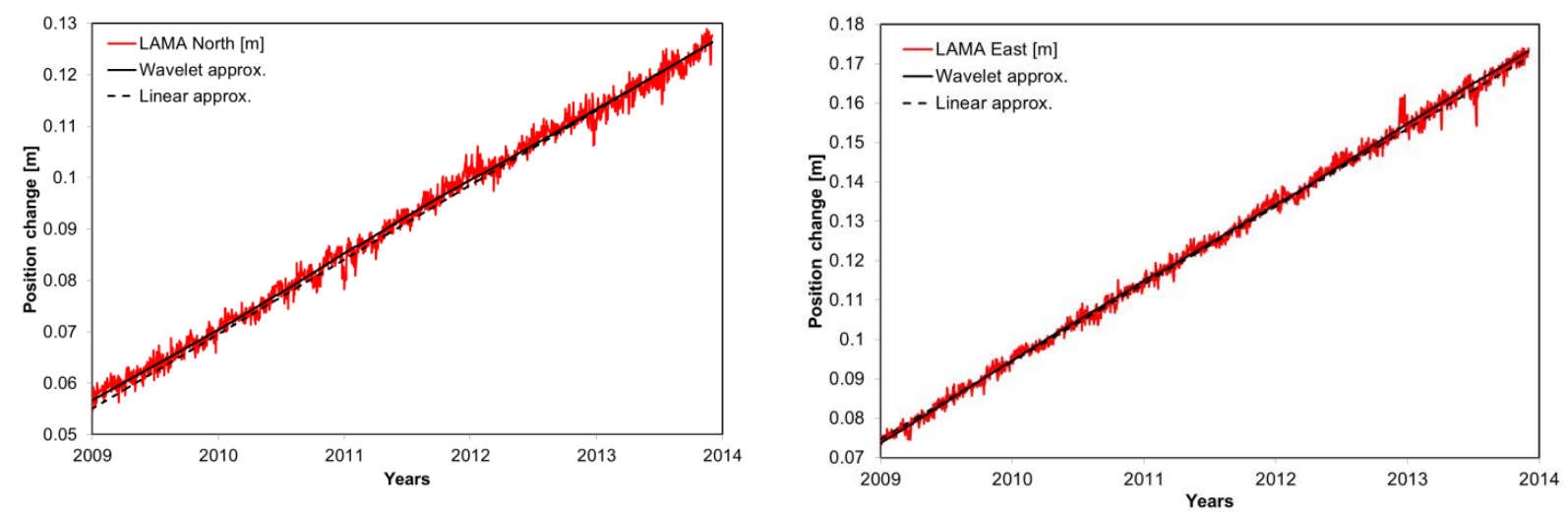

Fig. 3 Changes of LAMA (Lamkowko, Poland) North (left) and East (right) components [m]. The wavelet approximation A9 is represented by a solid line, linear fit with a dashed one.

\section{ANALYSIS AND RESULTS}

The following examples were taken from more than 3000 worldwide stations available on the JPL web site (ftp://sideshow.jpl.nasa.gov), the time series come from IGS Data Reprocessing Campaign 2011. Several of them are located in the vicinity of over 55 thousand kilometers of subduction zones around the world (Fig. 2), but most of the time series from these stations are not suitable for further analysis. They are very noisy, contain gaps, numerous steps and earthquakes, which are common in tectonically unstable areas.

To assess the degree of non-linearity, the coefficient of determination was used here, denoted as $R^{2}$, which is a number that indicates how well data fits a statistical model. It provides here a measure of how well wavelet-based approximation of the observed components are replicated by the linear model, as the proportion of total variation of them explained by the model.The most general definition of the coefficient of determination is:

$$
R^{2}=\frac{\sum_{i}\left(y_{i}-f_{i}\right)^{2}}{\sum_{i}\left(y_{i}-\bar{y}\right)^{2}}
$$

with residual sum of squares ( $f$ denotes linear function) in the numerator and total sum of squares in the denominator.

Before showing examples of non-linearity the time series from the station located in a tectonically stable region will be presented. I chose LAMA (Lamkowko, Poland) located on the East European Craton (EEC), which is the core of the Baltica protoplate with relatively rigid structure and thickness of ca. $50 \mathrm{~km}$. Figure 3 presents changes of the North and East components from 2007 till the end of 2014 with wavelet approximation A9 and linear approximation presented. For better reception only 5 years were presented. The motion of the Eurasian Plate in the North-East direction could be noticed. Differences between wavelet-based and linear approximation are not significant, while $R^{2}$ coefficient of determination is equal to 0.9997 and 0.9998 for North and East component, respectively.

Next part of this paper denotes non-linearity in GNSS-derived time series. In Figures 4-9 the chosen topocentric components are presented. Selection of specific two components was due to the absence of non-linearity in the third one, as described in the first chapter and presented graphically in Figure 1 . However, in Table 2 summarizing the obtained results, values for all three components are juxtaposed.

The first example chosen is the permanent GNSS station UNSA (Salta, Argentina). It is located near the subducting Nazca Plate, which exhibits flat-slab subduction, it is tearing as well as deforming in this process (Barzangi and Isacks, 1976). The subduction is forming the Central Volcanic Zone, being a part of the Andean Volcanic Belt, one of the major volcanic belts in the world. This region has a large potential for volcano-tectonic movement, such as rift systems, transpressional faults and subduction of mid-ocean trenches (Stern, 2004). The consistent GPS data from UNSA station covers the period from mid-2001 until the end of 2014 (13.2 years). Figure 4 presents daily changes of East and Up components. In this case the $R^{2}$ for A9 approximations reaches the values of 0.4686 and 0.4664 for East and Up component, respectively, while a maximum peak-to-peak deviation from the linearity was equal to: 2.2 and $1.0 \mathrm{~cm}$ (compare Table 2). The A9 for UNSA station gives clear evidence, that what is being left behind in data beyond the removal of commonly assumed residual oscillations (details from 1 to 9), has still some period, causing the approximation non-linearity. Moreover, the observed oscillations are irregular both in amplitude and phase, which undoubtedly directly influences not only the value of velocity uncertainty, but also the velocity itself. This can be observed especially for the East component, where the most extreme peak-to-peak deviation of $2.2 \mathrm{~cm}$ seems to be significant in terms of constantly growing demands on reliable velocities. 

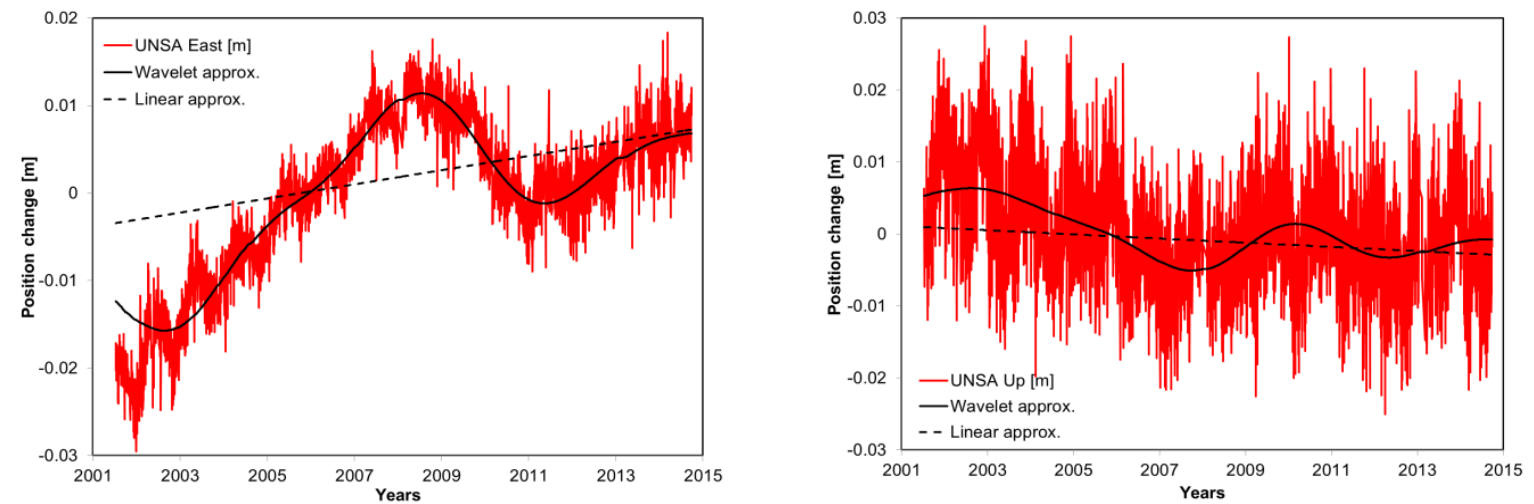

Fig. 4 Changes of UNSA (Salta, Argentina) East (left) and Up (right) components [m]. The wavelet approximation A9 is represented by a solid line, linear fit with a dashed one.
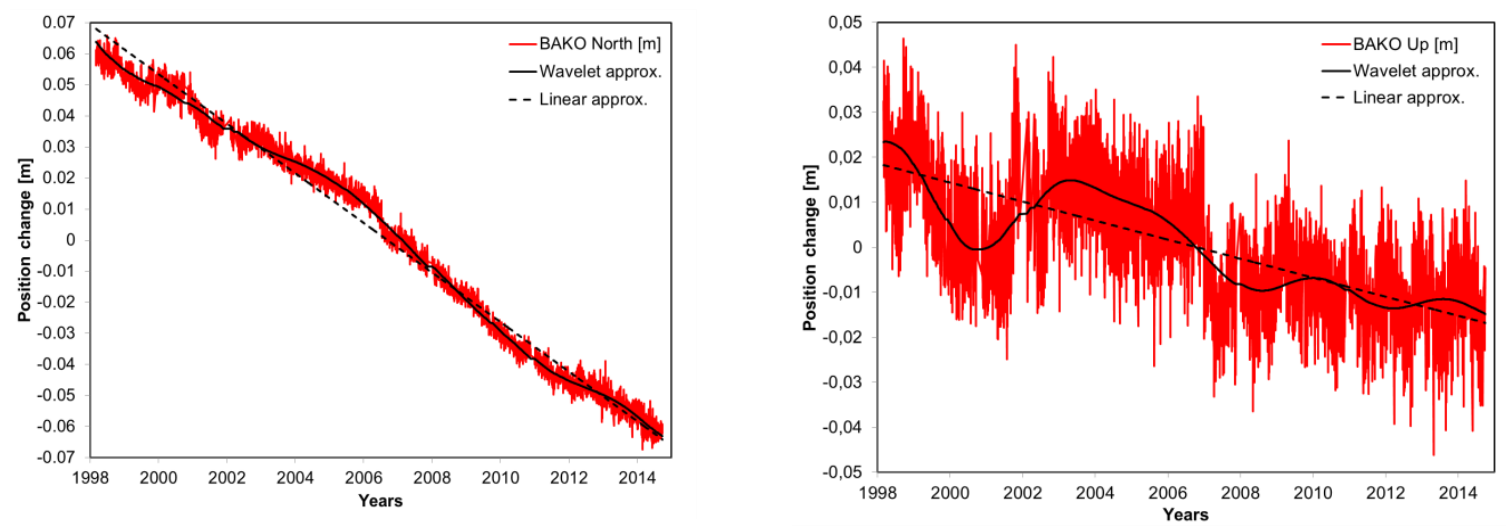

Fig. 5 Changes of BAKO (Cibinong, Indonesia) North (left) and Up (Right) components [m]. The wavelet approximation A9 is represented with a solid line, the linear fit with a dashed one.

The BAKO (Cibinong, Indonesia) permanent GNSS station serves as the second example. It is located in an area, where the Indo-Australian tectonic plate plunges under the Eurasian plate (Java trench). This region is one of the most active zones all over the world. Because the magma is hotter and less dense than the surrounding rocks it has the potential to migrate towards the surface, this region is also full of active volcanoes with a long history of eruptions. The consistent GPS data from this station covers the period from 1998 until the end of 2014 (16.6 years). Figure 5 presents daily changes of North and Up components (compare Table 2). In this case the $R^{2}$ for A9 reached 0.9908 and 0.7635 for North and Up components, respectively, while maximum peak-topeak deviation from the linearity was equal to: 1.3 and $2.1 \mathrm{~cm}$. Here, the non-linearity of last approximation changes with time. The peak-to-peak deviations are greater between 1999 and 2006, whilst becoming smaller from 2006 up to present. Here is of interest that the same increase in amplitude of A9 (with maximum equal to $0.5 \mathrm{~cm}$ ) can be noticed from 2001 to 2007 both for North and Up components.

CCJM (Ogasawara Islands) GNSS permanent station is the third example. This station lies in the
Izu-Bonin-Mariana arc system, lying along the eastern margin of the Philippine Sea Plate in the Western Pacific Ocean. This system was formed as the result of subduction of the Pacific Plate, which descends beneath the Philippine Sea Plate forming an intraoceanic convergent margin. The consistent GPS data from this station covers the period from 1996 until the beginning of 2011 (15.2 years). Figure 6 presents daily changes of East and Up components. In this case the $R^{2}$ reached 0.9980 and 0.8093 for East and $U p$ components (see Table 2), respectively, while a maximum peak-to-peak deviation from the linearity was equal to: 2.3 and $0.9 \mathrm{~cm}$. Although the amplitudes of non-linearity are not as high in comparison to linear approximation as it was in previous examples (especially for Up), they still remain varied in time and will have an influence on the station's linear velocity. A similar increase in A9 amplitude both for East and Up components can be noticed here firstly in 1997 and then close to 2010 .

The fourth example is the USUD (Usuda, Japan) GNSS permanent station located in a very dynamic area, where three tectonic plates (namely the Eurasian, the Philippine Sea, and the North American) meet one another. Additionally the Philippine Sea Plate 

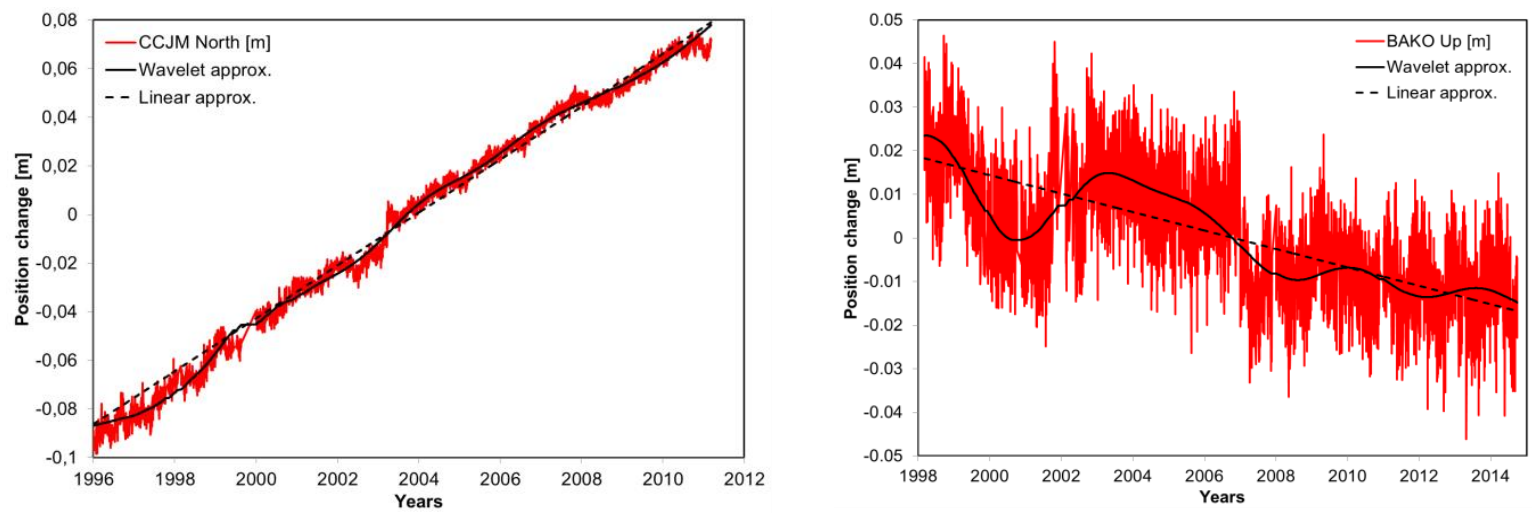

Fig. 6 Changes of CCJM (Ogasawara Islands) North (left) and Up (Right) components [m]. The wavelet approximation A9 is represented here with a solid line, linear fit with a dashed one.
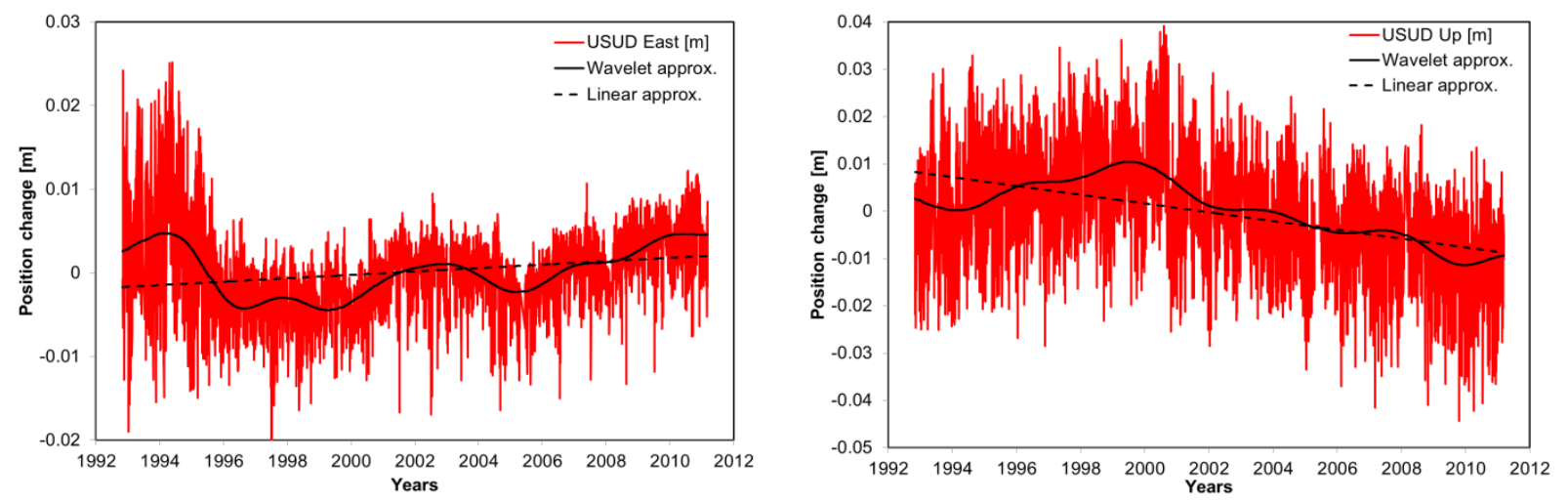

Fig. 8 Changes of USUD (Usuda, Japan) East (left) and Up (Right) components [m]. The wavelet approximation A9 is represented here with a solid line, linear fit with a dashed one.

descends beneath the Eurasian one (Figure 7). Furthermore this region is characterized by strong volcanic activity, that's why the Japanese Islands are part of volcanic islands arranged in several arcs. The consistent GPS data from this station covers the period from the end of 1992 until the beginning of 2011 (18.3 years). Figure 8 presents daily changes of East and Up components. In this case the $R^{2}$ reached 0.2752 and 0.6425 for East and Up components (see Table 2), respectively, while the maximum peak-topeak deviation from the linearity was equal to: 2.2 and $1.0 \mathrm{~cm}$. An extremely high peak-to-peak deviation for East component is caused mainly by the large amplitude in 1994. Then, the oscillations were smaller, but still remain varied in time. Omitting the growth in amplitude between 2000 and 2005, one may have an impression of trend non-linearity that initially slowly decreases in time up to 2000 to a surprisingly quick increase post 2005. The Up component may become an excellent example of trend non-linearity for stations located close to plate boundaries due to constantly growing values of time series (when ignoring the detected oscillations in A9) from 1993 up to 2000 and then their slow decrease up to 2011.
The fifth example is REYK (Reykjavik, Iceland) GNSS permanent station. It is situated on the North American Plate in the vicinity of the Mid-Atlantic Ridge, being a divergent tectonic plate boundary located along the floor of the Atlantic Ocean. This station serves as a reference datum for many geodynamic studies in this region (e.g. Árnadóttir et al., 2008; Keiding et al., 2008 or Völksen et al., 2009). As the visible symptom of the dynamics in this region numerous episodes of rifting by means of surface cracking can be observed. The consistent GPS data from this station covers the period from the beginning of 1996 until the mid of 2014 (18.6 years). Figure 9 presents daily changes of East and Up components. In this case the $R^{2}$ reached 0.9984 and 0.1463 for East and Up components (see Table 2), respectively, whilst the maximum peak-to-peak deviation from the linearity was equal to: 1.1 and $1.0 \mathrm{~cm}$. Although the peak-to-peak deviation is small in comparison to the scatter of the Up component, its influence on velocity value may still be seen. When ignoring the clearly seen oscillation in A9, the trend is decidedly non-linear for the Up component. It decreases between 1998 and 2000 to a slow increase from 2000 up to 2011 and then starts decreasing again. 
Table 2 The differences in trends and $R^{2}$ parameter for the considered stations.

\begin{tabular}{lccccccccc}
\hline Station & $\begin{array}{c}\mathbf{N} \\
\text { trend } \\
{[\mathrm{mm} / \mathrm{yr}]}\end{array}$ & $\begin{array}{c}\text { Na } \\
\text { trend } \\
{[\mathrm{mm} / \mathrm{yr}]}\end{array}$ & $\begin{array}{l}\text { Na } \\
\boldsymbol{R}^{\mathbf{2}}\end{array}$ & $\begin{array}{c}\mathbf{E} \\
\text { trend } \\
{[\mathrm{mm} / \mathrm{yr}]}\end{array}$ & $\begin{array}{c}\text { Ea } \\
\text { trend } \\
{[\mathrm{mm} / \mathrm{yr}]}\end{array}$ & $\begin{array}{c}\text { Ea } \\
\boldsymbol{R}^{2}\end{array}$ & $\begin{array}{c}\mathbf{U} \\
\text { trend } \\
{[\mathrm{mm} / \mathrm{yr}]}\end{array}$ & $\begin{array}{c}\text { Ua } \\
\text { trend } \\
{[\mathrm{mm} / \mathrm{yr}]}\end{array}$ & $\begin{array}{c}\text { Ua } \\
\boldsymbol{R}^{2}\end{array}$ \\
\hline BAKO & -8.0 & -7.8 & 0.9908 & 24.5 & 24.4 & 0.9995 & -2.1 & -2.0 & 0.7635 \\
CCJM & 10.9 & 11.3 & 0.9956 & -34.1 & -34.5 & 0.9980 & -0.8 & -1.0 & 0.8093 \\
LHAS & 15.9 & 15.8 & 0.9992 & 45.8 & 45.8 & 0.9997 & 0.8 & 0.6 & 0.6751 \\
LHAZ & 15.5 & 15.5 & 0.9999 & 47.2 & 47.2 & 0.9999 & 1.6 & 1.6 & 0.9627 \\
REYK & 21.1 & 21.3 & 0.9993 & -10.6 & -10.7 & 0.9984 & 0.3 & 0.2 & 0.1463 \\
UNSA & 12.1 & 12.0 & 0.9991 & 0.8 & 1.4 & 0.4686 & -0.3 & -0.6 & 0.4664 \\
USUD & -8.5 & -8.5 & 0.9813 & 0.2 & 0.2 & 0.2752 & -0.9 & -1.0 & 0.6425 \\
\hline
\end{tabular}
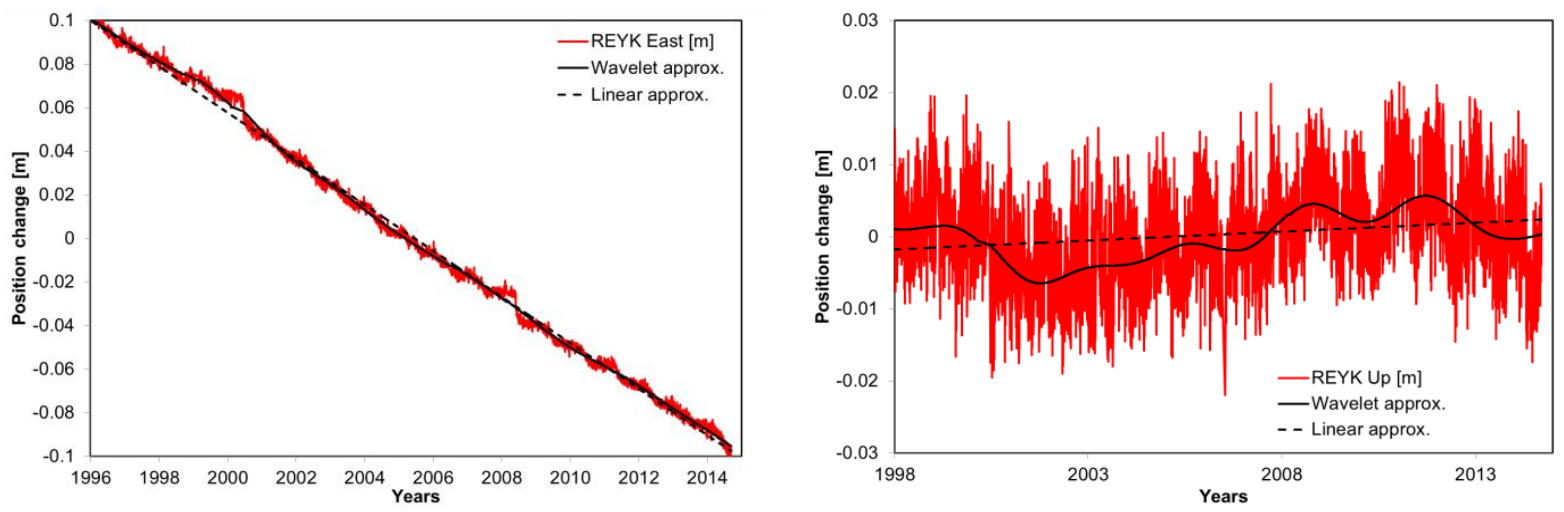

Fig. 9 Changes of REYK (Reykjavik, Iceland) East (left) and Up (right) components [m]. The wavelet approximation A9 is represented here with a solid line, linear fit with a dashed one.

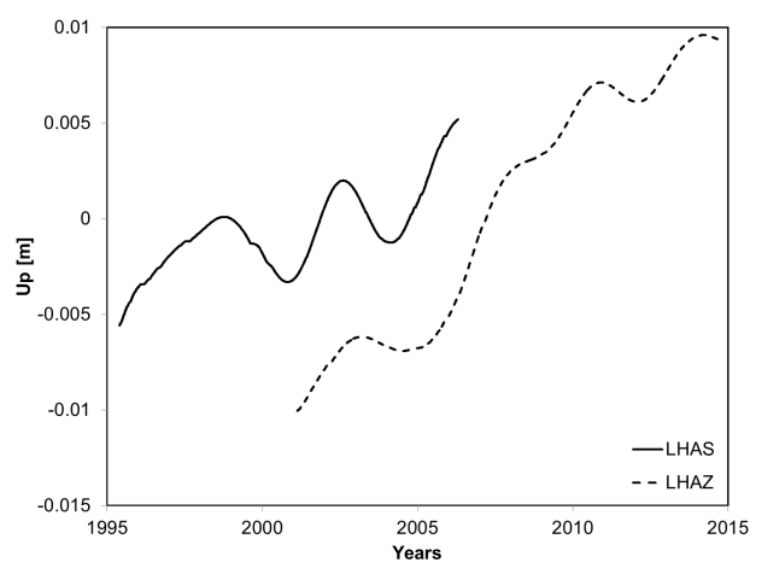

Fig. 10 Comparison of Up [m] wavelet approximation from LHAZ and LHAS permanent stations. The solid line represents A9 approximation of LHAZ stations, the dashed one of LHAS A9 for Up component.
In the case of GPS observations we always have to keep in mind the problem of reliability, due largely to systematic errors. We made our verification on two stations LHAS and LHAZ (Lhasa, Tibet/China), located only 4 metres from one another. This region is a classic example of plate collision (Indo-Australian Plate colliding with the Eurasian Plate), which forms fold mountains. The ongoing active collision of these two continental plates creates mountain ranges that are being continuously uplifted, but also collapsing under their own weight and worn down. The consistent GPS data from the station LHAS covers the period from mid-1995 until the mid of 2006 (10.7 years), whereas from LHAZ: from the beginning of 2001 until the end of 2014 (14 years). Figure 10 presents A9 approximations of the Up component (no non-linearity have been observed in North and East position changes). Although slightly greater amplitude could be observed at the station LHAS station, a Pearson correlation coefficient (Pearson, 1896) of the common period of observations ( 5.3 years) is $91.9 \%$. This double station provides clear evidence that the detected non-linearity in time series trend for stations situated near plate boundaries is due to real geodynamical effects, rather than artificial ones. In the case of LHAS and LHAZ 
we can notice the trend represented by A9 approximation varies in time on both stations with evident local extremes. Two stations situated next to each other recording similar long-term changes at the same time strongly prove the possible trend nonlinearity for stations in tectonically active areas.

From geodetic point of view the assumption of trend linearity may bring about the misestimation of its value with an influence on its uncertainty. Table 2 summarizes the differences in linear trends determined two-fold: from original pre-analysed data ( $\mathrm{N}$ trend, $\mathrm{E}$ trend and $\mathrm{U}$ trend) and from the wavelet approximation ( $\mathrm{Na}$ trend, Ea trend and $\mathrm{Ua}$ trend). The maximum difference is $0.6 \mathrm{~mm} / \mathrm{yr}$, which having regard to the length of today's GPS time series (even 23 years long concerning JPL database) seems to be a significant value.

\section{SUMMARY}

The reliability of station's velocity components depends mostly on the modelling of the deterministic part and the assumption of optimal character of time series residua. The first one consists of outliers and offset removal (due to instrument changes or local deformations, like earthquakes), these may lead to wrong interpretations in time series character, etc. (e.g. Klos et al., 2014; 2015), then most reliable is seasonal and trend modelling. Papers published so far indicate that incorrect assumptions on a number of sine terms present in a time series may result in overestimation of velocity uncertainty (Bos et al., 2010) or even in a change of the velocity value itself (Davis et al., 2012). Conversely this means that unrealistic assumption of the character of the time series residua may underestimate the velocity uncertainty by a factor of 2 to even 11 times (Zhang et al., 1997; Mao et al., 1999; Williams et al., 2004).

Non-linearity of the GPS-derived velocities is not evident, but cannot be excluded, especially in the tectonically active regions, like subduction and spreading zones. It is claimed that wavelet decomposition is the ultimate method for investigating non-linearity, because either details or approximation are non-linear. However this method does not bring uncertainties, which is an obvious disadvantage, but we can support it with some additional simulations.

Presently the majority of the determinations of dynamics using GNSS satellites is performed by the solution of the linear equation system, but the geodetic community is well aware of non-linear effects at sites in deforming zones, and that these sites should not be used to define a reliable global reference frame at the desired level of uncertainty. But the GPSderived velocity inversions using wavelet-derived approximation could be successfully compared to the elastic deformation that predicts e.g. finite element modelling that approximates the geometry of the subduction, spreading or transition zones.

\section{ACKNOWLEDGMENTS}

This research was financed by the Polish National Science Centre, grant No. UMO2014/15/B/ST10/03850.

JPL repro2011b time series accessed from ftp://sideshow.jpl.nasa.gov/pub/JPL_GPS_Timeseries/ repro2011b/raw/on 2014-11-10.

Ms. Anna Klos is most gratefully acknowledged for her support in data analysis.

Maps and figures were drawn using the Generic Mapping Tool.

I would like to address many thanks to the anonymous reviewers for their very careful reading and issuing a number of comments, which helped to improve the paper.

\section{REFERENCES}

Agnew, D.C. and Larson, K.M.: 2007, Finding the repeat times of the GPS constellation. GPS Solut., 11, 71-76. DOI: 10.1007/s10291-006-0038-4

Altamimi, Z., Collilieux, X. and Métivier, L.: 2011, ITRF2008: an improved solution of the International Terrestrial Reference Frame. J. Geodesy, 85, No. 8, 457-473. DOI: 10.1007/s00190-011-0444-4

Altamimi, Z., Métivier, L. and Collilieux, X.: 2012, ITRF2008 Plate Motion Model. J. Geophys. Res., 117, No. B07402. DOI: 10.1029/2011JB008930

Amiri-Simkooei, A.R.: 2013, On the nature of GPS draconitic year periodic pattern in multivariate position time series. J. Geophys. Res., Solid Earth, 118, 2500-2511. DOI: 10.1002/jgrb.50199

Árnadóttir, T., Geirsson, H. and Jiang, W.: 2008, Crustal deformation in Iceland: Plate spreading and earthquake deformation. Jökull, No. 58, 59-74.

Barazangi, M. and Isacks, B.L.: 1976, Spatial distribution of earthquakes and subduction of the Nazca plate beneath South America. Geology, 4, No. 11, 686-692.

Blewitt, G. and Lavallée, D.: 2002, Effect of annual signals on geodetic velocity. J. Geophys. Res., 107, B7, 2145. DOI: 10.1029/2001JB000570

Bogusz, J. and Figurski, M.: 2012, GPS-derived height changes in diurnal and sub-diurnal timescales. Acta Geophysica, 60, No. 2, 295-317. DOI:10.2478/s11600-011-0074-5

Bogusz, J. and Figurski, M.: 2014, Annual signals observed in regional GPS networks. Acta Geodyn. Geomater., 11, No. 2(174), 125-131. DOI: 10.13168/AGG.2014.0003

Bos, M.S., Bastos, L. and Fernandes, R.M.S.: 2010, The influence of seasonal signals on the estimation of the tectonic motion in short continuous GPS time-series. J. Geodyn., 49, 205-209. DOI: 10.1016/j.jog.2009.10.005

ten Brink, U.S. and López-Venegas, A. M.: 2012, Plate interaction in the NE Caribbean subduction zone from continuous GPS observations. Geophys. Res. Lett., 39, L10304. DOI: 10.1029/2012GL051485

Bruni, S., Zerbini, S., Raicich, F., Errico, M. and Santi, E.: 2014, Detecting discontinuities in GNSS coordinate time series with STARS: case study, the Bologna and Medicina GPS sites. J. Geodesy, 88, No. 12, 12031214. DOI: 10.1007/s00190-014-0754-4, 2014

Bruyninx, C., Altamimi, Z., Caporali, A., Kenyeres, A., Lidberg, M., Stangl, G., and Torres, J.A.: 2013, 
Guidelines for EUREF Densifications. Available electronically at $\mathrm{ftp} / /$ epncb.oma.be/pub/general/. Downloaded on 23.12.2014.

Caporali, A., Neubauer, F., Ostini, L., Stangl, G. and Zuliani, D.: 2013, Modeling surface GPS velocities in the Southern and Eastern Alps by finite dislocations at crustal depths. Tectonophysics, 590, 136-150.

DOI: 10.1016/j.tecto.2013.01.016

Chlieh, M., de Chabalier, J.B., Ruegg, J.C., Armijo, R., Dmowska, R., Campos, J. and Feigl, K.L.: 2004, Crustal deformation and fault slip during the seismic cycle in the North Chile subduction zone, from GPS and InSAR observations. Geophys. J. Int., 158, No. 2, 695-711. DOI: 10.1111/j.1365-246X.2004.02326.x

Collilieux, X., Altamimi, Z., Coulot, D., Ray, J. and Sillard, P.: 2007, Comparison of very long baseline interferometry, GPS, and satellite laser ranging height residuals from ITRF2005 using spectral and correlation methods. J. Geophys. Res., 112, B12403. DOI: $10.1029 / 2007$ JB004933

Collin, F. and Warnant, R.: 1995, Applications of the wavelet transform for GPS cycle slip correction and comparison with Kalman filter. Manuscripta Geodaetica, 20, 161-172.

Correa-Mora, F., DeMets, C., Alvarado, D., Turner, H. L., Mattioli, G., Hernandez, D., Pullinger, C., Rodriguez, M. and Tenorio, C.: 2009, GPS-derived coupling estimates for the Central America subduction zone and volcanic arc faults: El Salvador, Honduras and Nicaragua. Geophys. J. Int., 179, 1279-1291. DOI: $10.1111 / \mathrm{j} .1365-246 X .2009 .04371 . x$

Cross, R.S. and Freymueller, J. T.: 2007, Plate coupling variation and block translation in the Andreanof segment of the Aleutian arc determined by subduction zone modeling using GPS data. Geophys. Res. Lett., 34, L06304. DOI: 10.1029/2006GL028970

Davis, J.L., Wernicke, B.P. and Tamisiea, M.E.: 2012, On seasonal signals in geodetic time series. J. Geophys. Res., 117, B01403. DOI: 10.1029/2011JB008690

Dong, D., Fang, P., Bock, Y., Cheng, M.K. and Miyazaki, S.: 2002, Anatomy of apparent seasonal variations from GPS-derived site position time series. J. Geophys. Res., Solid Earth, 107, No. B4, 2075. DOI: 10.1029/2001JB000573

Erdoğan, S., Şahin, M., Tiryakioğlu, İ., Gülal, E. and Telli, A.K.: 2009, GPS velocity and strain rate fields in southwest Anatolia from repeated GPS measurements. Sensors, 9, 2017-2034. DOI: 10.3390/s90302017

Figurski, M., Szafranek, K., Bogusz, J. and Kamiński, P.: 2010, Investigation on stability of mountainous EUPOS sites' coordinates. Acta Geodyn. Geometer., 7, No. 3 (159), 263-274.

Frisch, W., Meschede, M. and Blakey, R.: 2011, Plate Tectonics. Continental Drift and Mountain Building. Springer Heidelberg Dordrecht London New York. DOI: 10.1007/978-3-540-76504-2

Gazeaux, J., Williams, S., King, M., Bos, M., Dach, R., Deo, M., Moore, A.W., Ostini, .L, Petrie, E., Roggero, M., Teferle, F.N., Olivares, G. and Webb, F.H.: 2013, Detecting offsets in GPS time series: first results from the detection of offsets in GPS experiment. J. Geophys. Res., Solid Earth, 118, 2397-2407. DOI: 10.1002/jgrb.50152

Griffiths, J. and Ray, J.R.: 2013, Sub-daily alias and draconitic errors in the IGS orbits. GPS Solut., 17, 413-422. DOI: 10.1007/s10291-012-0289-1
Gross, R., Beutler, G., and Plag, H.-P.: 2009, Integrated scientific and societal user requirements and functional specifications for the GGOS. In "Global Geodetic Observing System Meeting the Requirements of a Global Society on a Changing Planet in 2020" edited by Hans-Peter Plag and Michael Pearlman, Springer Dordrecht Heidelberg London New York. DOI: 10.1007/978-3-642-02687-4

Hashimoto, C., Noda, A., Sagiya, T. and Matsu'ura, M.: 2009, Interplate seismogenic zones along the KurilJapan trench inferred from GPS data inversion. Natur. Geosci., 2, 141-144. DOI: 10.1038/ngeo421

Herring, T.: 1998, Documentation for GLOBK: Global Kalman Filterfor VLBI and GPS Analysis Program, version 4.1. MIT, Cambridge, MA.

Husson, L.: 2012, Trench migration and upper plate strain over a convecting mantle. Phys. Earth Planet. Inter., 212-213, 32-43. DOI: 10.1016/j.pepi.2012.09.006

Keiding, M., Árnadóttir, T., Sturkell, E., Geirsson, H. and Lund, B.: 2008, Strain accumulation along an oblique plate boundary: The Reykjanes Peninsula, southwest Iceland. Geophys. J. Int., 172, No. 1, 861-872. DOI: $10.1111 /$ j.1365-246X.2007.03655.x

Keller, W.: 2004, Wavelets in geodesy and geodynamics. Walter de Gruyter GmbH \& Co, 289 pp.

Klos, A., Bogusz, J., Figurski, M. and Kosek, W.: 2014, Irregular variations in the GPS time series by the probability and noise analysis. Survey Review. DOI: 10.1179/1752270614Y.0000000133

Klos, A., Bogusz, J., Figurski, M. and Kosek, W.: 2015, On the handling of outliers in the GNSS time series by the noise and probability analysis. Springer IAG Symposium Series, 143, Proceedings of the IAG Scientific Assembly 2013. DOI: $10.1007 / 1345 \_2015 \_78$

Kreemer, C., Blewitt, G. and Klein, E. C.: 2014, A geodetic plate motion and global strain rate model. Geochem. Geophys. Geosyst., 15, 3849-3889. DOI: $10.1002 / 2014 \mathrm{GC} 005407$

Mallat, S: 1989, A theory for multiresolution signal decomposition: the wavelet representation. IEEE Transactions on Pattern Recognition and Machine Intelligence, 11, No. 7, 674-693. DOI: $10.1109 / 34.192463$

Mann, P., Calais, E., Ruegg, J.-C., DeMets, C, Jansma, P.E. and Mattioli, G.S.: 2002, Oblique collision in the northeastern Caribbean from GPS measurements and geological observations. Tectonics, 21, No. 6, 1057. DOI: 10.1029/2001TC001304

Mao, A., Harrison, Ch.G.A. and Dixon, T.H.: 1999, Noise in GPS coordinate time series. J. Geophys. Res., 104, No. B2, 2797-2816.

Meyer, Y.: 1990, Ondelettes et Opérateurs, Hermann.

Pearson, K.: 1896, Mathematical contributions to the theory of evolution. III. Regression, heredity, and panmixia. Philosophical Transactions of the Royal Society, Ser. A, 187, 253-318.

Penna, N. T. and Stewart, M. P.: 2003, Aliased tidal signatures in continuous GPS height time series. Geophys. Res. Lett., 30, No. 23, 2184. DOI: $10.1029 / 2003$ GL018828

Pérez-Peña, A., Martín-Davila, J., Gárate, J., Berrocoso, M. and Buforn, E.: 2010, Velocity field and tectonic strain in Southern Spain and surrounding areas derived from GPS episodic measurements. J. Geodyn., 49, No. 3-4, 232-240. DOI: 10.1016/j.jog.2010.01.015 
Popinski, W.: 1996, Wavelet transform for time-frequency representation and filtration of discrete signals. Applicationes Mathematicae, Warszawa-Wroclaw, 23, No. 4, 433-448.

Ray, J., Altamimi, Z., Collilieux, X. and van Dam, T.: 2008, Anomalous harmonics in the spectra of GPS position estimates. GPS Solut., 12, 55-64. DOI: $10.1007 / \mathrm{s} 10291-007-0067-7$

Satirapod, C., Ogaja, C., Wang, J. and Rizos, C.: 2001, An approach to GPS analysis incorporating wavelet decomposition. Artificial Satellites, 36, 27-35.

Sella, G.F., Dixon,T.H. and Mao, A.: 2002, REVEL: A model for recent plate velocities from space geodesy. J. Geophys. Res., 107, B4. DOI: $10.1029 / 2000 J B 000033$

Shih, D.C.F., Wu, Y.M., Lin, G.F., Hu, J.C., Chen, Y.G. and Chang, C.H.: 2008, Assessment of long-term variation in displacement for a GPS site adjacent to a transition zone between collision and subduction. Stochastic Environmental Research and Risk Assessment, 22, No. 3, 401-410. DOI: 10.1007/s00477-007-0128-Z

Steblov, G.M., Vasilenko, N.F, Prytkov, A.S., Frolov, D.I. and Grekova, T.A: 2010, Dynamics of the KurilKamchatka subduction zone from GPS data. Physics of the Solid Earth, 46, No. 5, 440-445. DOI: $10.1134 / \mathrm{S} 1069351310050095$

Stern, C.R.: 2004, Active Andean volcanism: its geologic and tectonic setting. Revista Geológica de Chile, 31, No. 2, 161-206. DOI: $10.4067 / S 0716-02082004000200001$

de Souza, E.M., Monico, J.F.G. and Pagamisse, A.: 2009, GPS satellite kinematic relative positioning: Analyzing and improving the functional mathematical model using wavelets. Mathematical Problems in Engineering, No. 934524. DOI: 10.1155/2009/934524

Turner, H.L.I., LaFemina, P., Saballos, A., Mattioli, G.S., Jansma, P.E. and Dixon, T.: 2007, Kinematics of the Nicaraguan forearc from GPS geodesy. Geophys. Res. Lett., 34, L02302. DOI: 10.1029/2006GL027586

Völksen, C., Árnadóttir, T., Geirsson, H. and Valsson, G.: 2009, Present day geodynamics in Iceland monitored by a permanent network of continuous GPS stations. J. Geodyn. 48, 270-283.

DOI: $10.1016 /$ j.jog.2009.09.033
Wang, J., Luan, X. and Yu, R.Z.: 2013, Modern movement and deformation in the South China Sea shown by GPS measurements and numerical simulation. Chinese Journal of Oceanology and Limnology, 31, No. 1, $159-168$.

Webb, F.H. and Zumberge, J.F.: 1997, An introduction to GIPSY/OASIS II. JPL Publication D-11088.

Williams, S.D.P.: 2003, Offsets in Global Positioning System time series. J. Geophys. Res., 108, B6, 2310. DOI: 10.1029/2002JB002156

Williams, S.D.P., Bock, Y., Fang, P., Jamason, P., Nikolaidis, R.M., Prawirodirdjo, L., Miller M. and Johnson, D.: 2004, Error analysis of continuous GPS position time series. J. Geophys. Res., 109, B03412. DOI: 10.1029/2003JB002741

Yoshioka, S., Mikumo, T., Kostoglodov, V., Larson, K.M., Lowry, A.R. and Singh, S.K.: 2004, Interplate coupling and a recent aseismic slow slip event in the Guerrero seismic gap of the Mexican subduction zone, as deduced from GPS data inversion using a Bayesian information criterion. Physics of the Earth and Planetary Interiors, 146, No. 3-4, 513-530. DOI: 10.1016/j.pepi.2004.05.006

Zhang, J., Bock, Y., Johnson, H., Fang, P., Williams, S., Genrich, J., Wdowinski, S. and Behr, J.: 1997, Southern California permanent GPS geodetic array: Error analysis of daily position estimates and site velocities. J. Geophys. Res., 102, No. B8, 18,03518,055. DOI: $10.1029 / 97 J B 01380$

http://earthquake.usgs.gov 


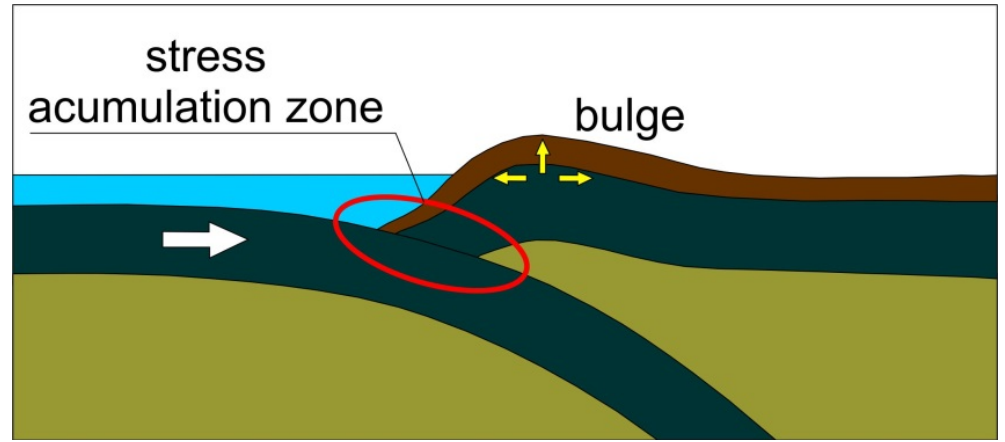

Fig. 1 Coupling at the plate boundaries (modified follow Frisch et al., 2011).

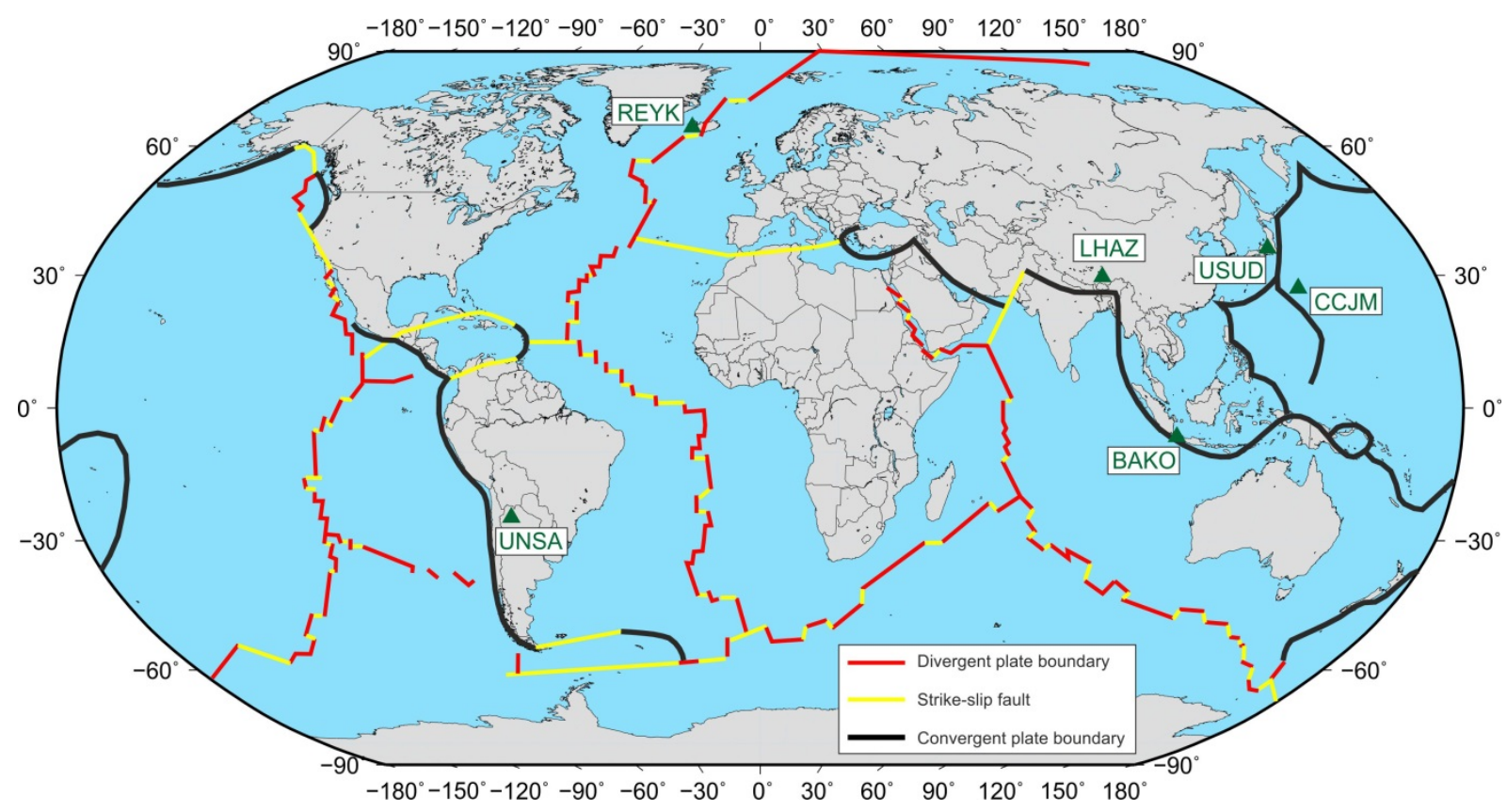

Fig. 2 A map of IGS GPS stations taken in analysis (green triangles) of the major plate boundaries.

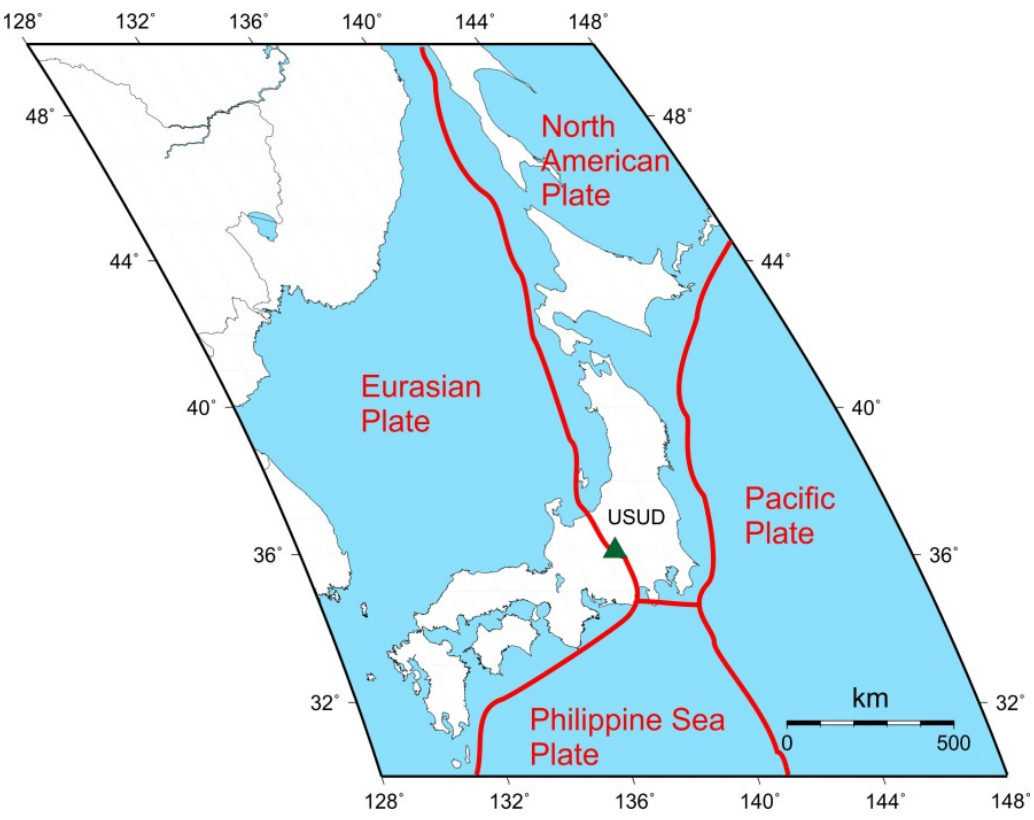

Fig. 7 Location of USUD (Usuda, Japan) GNSS permanent stationwith approximate borders of main tectonic structures. 